DOI: http://dx.doi.org/10.20435/1192

\title{
A busca pelo reconhecimento da identidade étnica Macuxi e Wapichana no contexto urbano de Boa Vista, Roraima, Brasil
}

\begin{abstract}
The search for ethnic Macuxi and Wapichana identity recognition in the Boa Vista urban context, Roraima, Brazi
\end{abstract}

Ana Hilda Carvalho Souza ${ }^{1}$

Claus Haetinger ${ }^{2}$

Luís Fernando da Silva Laroque ${ }^{3}$

${ }^{1}$ Doutoranda em Ambiente e Desenvolvimento - Centro Universitário UNIVATES. E-mail: anahildarr@hotmail.com

${ }^{2}$ Doutor em Matemática (UFRGS). Professor e pesquisador do Programa de Mestrado e Doutorado em Ambiente e Desenvolvimento do Centro Universitário UNIVATES, Lajeado, RS.E-mail: chaet@univates.br

${ }^{3}$ Doutor em História (UNISINOS). Professor de Pós-Graduação do Programa em do Programa de Mestrado e Doutorado em Ambiente e Desenvolvimento do Centro Universitário UNIVATES. E-mail: lflaroque@univates.br 


\section{RESUMO}

O objetivo deste artigo é apresentar uma discussão sobre a busca de validação da identidade indígena Macuxi e Wapichana, frente ao contexto sócio-histórico e espacial da cidade de Boa Vista, capital de Roraima. Esses grupos étnicos fazem parte dos povos habitantes ancestrais da região de Tríplice Fronteira do Extremo

Norte do Brasil, que, desde a incursão da sociedade não indígena na ocupação de seus territórios, vêm passando por um impactante processo de construção, desconstrução e reconstrução de sua identidade étnica. Está fundamentado na leitura de ambientes que demarcam as atuações dos sujeitos em situação de conflitos socioculturais. Esses grupos étnicos vem-se tornando protagonistas de sua própria legitimidade, em detrimento da invisibilidade a que foram histórica e culturalmente submetidos. Por meio de uma metodologia qualitativa em entrevista semiestruturada, buscou-se fazer interpretações dos significados das experiências vividas no contexto socioespacial da área urbana de Boa Vista. Verificou-se que os Macuxi e Wapichana, utilizam-se das identidades a eles atribuída pela sociedade não indígena, mesmo construída sob perspectiva etnocêntrica, como elemento de ressignificação para validar sua presença em área urbana. Por outro

lado, mesmo em processo de embate com a ainda cultura da sobreposição, reivindicam, lutam e buscam manter sua alteridade na reconquista de seus direitos históricos e culturais.

\section{PALAVRAS-CHAVE}

\author{
cidade \\ identidade étnica \\ ressignificação cultura
}

\section{ABSTRACT}

The aim of this article is to present a discussion about the reach for validation of the Makushi Indigenous and Wapichana, against the sociohistorical and spatial context of the city of Boa Vista, Roraima. These ethinic groups are part of the peoples ancestral inhabitants of the Triple Frontier region of the Far North Brazil, which, since the incursion of non-indigenous society in the occupation of their territories, have been going through an impressive process of construction, deconstruction and reconstruction of their ethnic identity. It is based on reading environments that demarcate the actions of individuals in a situation of socio-cultural conflicts. These ethnic groups have becoming protagonists of their own legitimacy, to the detriment of invisibility that were historically and culturally submitted. Through a qualitative methodology in semistructured interview, It has sought to make interpretations of the meanings of experiences in socio-spatial context of the urban area in Boa Vista. It found that the Makushi and Wapichana use the identities attributed to them by non-indigenous society, even built under ethnocentric perspective as reframing element to validate their presence in urban areas. On the other hand, even in clash process with even culture overlap, claim, struggle and seek to maintain their otherness in the reconquest of their historical and cultural rights..

\section{KEY WORDS}

\author{
city \\ ethnic identity \\ cultural reframing
}




\section{INTRODUÇÃo}

A presença indígena nas cidades brasileiras impacta a área acadêmica para se discutir os processos identitários que se fundem nas relações destes com a sociedade não indígena. Esse fenômeno, no âmbito das ciências ambientais, envolve temas que demarcam atuações de sujeitos em situação de conflitos socioculturais e ambientais. Este artigo busca fazer uma discussão sobre a validação da identidade indígena Macuxi e Wapichana, junto ao contexto sócio-histórico e espacial da cidade de Boa Vista, capital de Roraima. Esse grupos étnicos, enquanto sujeitos, são "animados" por um conjunto de modos de percepção, afeto, pensamento, desejo, que os impulsionam a tornarem-se reconhecidos dentro da estrutura social urbana. Nesse ambiente, em processo de ressignificação cultural, utilizam seu protagonismo sócio-histórico, para legitimar sua identidade étnica e assegurar sua sobrevivência urbana.

A presença indígena em áreas urbanas não se trata de uma realidade apenas regional, mas também nacional e internacional, cujos conflitos, nas relações socioculturais, tendem a se agravar, se analisados por perspectivas etnocêntricas. No âmbito local, nacional e internacional, pode-se destacar diversas situações em que esses grupos humanos, embora, delimitados culturalmente, optaram por se autoconstruir dentro de um sistema social abrangente. Nesse sentido, Lappe (2015) destaca as espacialidades sociais e territoriais a partir de um olhar das coletividades Kaingang, Terras Indígenas no Rio Grande do Sul, no sentido da continuidade dos seus costumes, crenças e rituais no processo de contato com a sociedade não indígena. Já Mussi (2006) analisa as estratégias de inserção construída pelos Terenas em Mato Grosso, para inserção e negociação no entorno da sociedade não indígena.

No âmbito mundial, o Programa das Nações Unidas para os Assentamentos Humanos (UN-HABITAT, 2010, p. 28), alerta que, 
na Guatemala e no México, "cerca de uma em cada três pessoas são indígenas que vivem em áreas urbanas", enquanto que em países como Austrália, Canadá, Chile, Estados Unidos, Noruega, Quênia e Nova Zelândia, mais da metade da população nativa vive em cidades (particularmente no Chile, onde a proporção sobe para 64,8\%).

Para a América Latina, os dados quantitativos do Censo de 2000 apontam que dos 30 milhões de indígenas no território de vários países, 12 milhões residem em área urbana. No Brasil, a população indígena no território nacional soma 896,9 mil pessoas, sendo que 36,2\% residem na área urbana, e 63,8\%, na rural (INSTITUTO BRASILEIRO DE GEOGRAFIA E ESTATÍSTICA [IBGE], 2012). A maior parcela de indígenas residentes fora das terras indígenas, em termos absolutos, correspondeu à Região Nordeste. São 126 mil indígenas, com um peso relativo de 33,4\%, porém, a maior concentração urbana está na Região Sudoeste (IBGE, 2012).

A Região Norte, com 342 mil indígenas, revela-se com o maior contingente indígenas no Brasil. É explícita a dimensão desses grupos que habitam as Terras Indígenas (TIs), revelados no percentual de 48,7\% em relação ao total de indígenas residentes no território nacional. Porém, para a região, a maior concentração se encontra na área rural, com 82\%, e, nas cidades, 18\% (IBGE, 2012).

No estado de Roraima, cerca de $11 \%$ da população geral declaram-se indígenas, segundo o (IBGE, 2012). Porém, para esse contingente, reinam imprecisões e divergências em relação ao quantitativo para aqueles que residem na cidade de Boa Vista. Segundo Frank (2014), essas discrepâncias quantitativas são indicativos da necessidade de investimento em investigações de maior escopo, com metodologias bem arquitetadas e categorias bem definidas na perspectiva de superar tais lacunas.

Entre as várias divergências nas estimativas demográficas, aponta-se Silveira e Souza (2011), que apontam, para o ano de 2008, uma população residente na ordem de 13 \%. Já o censo de 
2010 registrou apenas 6.072 pessoas que se identificam como indígenas no contexto urbano de Boa Vista. Embora apresentando um contingente inexato, esses números são importantes para que se possa ter uma dimensão, ainda que estimada, da urgência da produção de estudos que abordem as afirmações da identidade indígena que, sob vários aspectos, se processam diariamente nas cidades brasileiras.

\section{PROCEDIMENTOS METODOLÓGICOS}

Esta pesquisa se caracteriza como descritiva ao relatar as percepções que motivaram o protagonismo indígena na área urbana de Boa Vista. Elegeram-se os procedimentos qualitativos, pressupondo o entendimento de relação entre as experiências socioculturais construídas e as subjetividades do sujeito, que não poderiam ser traduzidas em números (TRIVIÑOS, 2001). Desse modo, utilizou-se da entrevista semiestruturada e etnografia mesmo relacional - esta segunda registrada em diário de campo, o que forneceu dados para conhecer como os indígenas que se encontram na cidade de Boa Vista vivenciam o dilema de transitoriedade entre a cidade e suas comunidades, bem como para eles se organizarem politicamente, na busca do fortalecimento para a identidade indígena.

O processo na construção das informações ocorreu pela proximidade com indígenas acadêmicos, o que levou ao contato com os protagonistas das organizações. Foram identificadas e pesquisadas líderes de três organizações: a Organização Indígena da Cidade (ODIC), a Associação Cultural Indígena do Estado de Roraima, denominada por Kapoi ${ }^{1}$ e a Associação Estadual Indígena Kuai'kri' ${ }^{2}$. Os sujeitos foram unânimes em contribuir espontanea-

\footnotetext{
${ }^{1} 0$ termo Kapoi significa lua na língua Macuxi.

${ }^{2}$ Kuai'kri, significa teso do buritizal ou parte mais alta da planta na língua Macuxi.
} 
mente com a pesquisa, conformando à percepção de que os indígenas fazem uso das produções acadêmicas como instrumentos que dão notoriedade para suas pautas reivindicatórias.

As entrevistas foram realizadas nas residências, também ocupadas como sede das organizações. Nesse instrumento de coleta de dados primário, os líderes ancoraram-se num roteiro que lhes permitisse uma visão crítica acerca das suas percepções na cidade. Porém, ao assumir seu papel na liderança, suas narrativas sintetizavam as experiências coletivas dos demais membros das agências.

Para os demais protagonistas indígenas, abordou-se primordialmente sua experiência pessoal e social na cidade, sua trajetória na agência indígena, enfatizando sua principal coatuação na defesa dos direitos indígenas. De forma geral, nos relatos desses interlocutores, não se percebeu uma autodenominação de povos minoritários em processo de libertação; o que se pode perceber é o desejo incessante por afirmação étnica e de seus direitos de cidadão.

As aproximações nos espaços de interação social indígena possibilitaram, antes, durante e após as entrevistas, um olhar profundo das experiências cotidianas dos indígenas, que sustentaram os relatos dos interlocutores. Segundo Pais (2003, p. 29), as “[...] rotas do quotidiano são caminhos denunciadores dos múltiplos meandros da vida social". Assim, pode-se fazer uma interpretação de questões relacionadas a sentimentos, motivações, crenças e atitudes individuais e coletivas dos indígenas.

A análise das informações constantes nas falas dos interlocutores deu-se mediante identificação das interpretações dos significados das experiências na cidade e necessidade de organização política em agências indígenas. Apoiado em Geertz (1989), a interpretação do fenômeno que norteia esta pesquisa, consiste apenas em uma tentativa de se chegar o mais próximo possível das interpretações das ressignificações dos sistemas culturais dos 
indígenas, orientado por suas subjetividades. 0 Quadro 1 a seguir traz um demonstrativo dos sujeitos colaboradores, as organizações indígenas em que atuam e suas comunidades de origem.

\begin{tabular}{|c|c|c|c|c|}
\hline Identificação & Etnia & $\begin{array}{c}\text { Membro da } \\
\text { Agência indígena }\end{array}$ & Local de origem/TI & País \\
\hline ES1 & Macuxi & ODIC & $\begin{array}{c}\text { Faz. Lago Grande/ } \\
\text { Manuá-Pium }\end{array}$ & Brasil \\
\hline ES2 & Wapichana & ODIC & $\begin{array}{c}\text { Potarinau (Ambrose)/ } \\
\text { Região } 9^{3}\end{array}$ & Guiana \\
\hline ES3 & Macuxi & Kuaikri & Ananai/São Marcos & Brasil \\
\hline ES4 & Macuxi & ODIC & $\begin{array}{c}\text { Awerwanaw Village/ } \\
\text { Região } 9\end{array}$ & Guiana \\
\hline ES5 & Wapichana & Kapoi & Lagos/Região 8 & Guiana \\
\hline ES6 & Wapichana & ODIC & $\begin{array}{c}\text { Xumina/Raposa Serra } \\
\text { do Sol }\end{array}$ & Brasil \\
\hline ES7 & Wapichana & ODIC & Malacacheta/Serra da Lua & Brasil \\
\hline ES8 & Wapichana & Kuaikri & Serra da Lua & Brasil \\
\hline ES9 & Wapichana & Kapoi & Muriru/Serra da Lua & Brasil \\
\hline ES10 & Macuxi & ODIC & $\begin{array}{c}\text { Mutum/Raposa Serra } \\
\text { do Sol }\end{array}$ & Brasil \\
\hline
\end{tabular}

Quadro 1 - Identificação étnica dos colaboradores da pesquisa

0 quadro retrata a diversidade de origem dos sujeitos entrevistados pertencentes pelo menos a uma das três agências indígenas pesquisadas. São dados que possibilitam uma leitura

\footnotetext{
${ }^{3}$ Frank (2014) traz uma configuração espacial da região da fronteiriça do Brasil com a Guiana Inglesa. Segundo a autora é exatamente na fronteira que estão os territórios tradicionais indígenas Wapichana e Macuxi, compartilhado com os três países. São aqueles localizados na região administrativa número 7 (em menor proporção com a parte brasileira). E as regiões 8 e 9 localizam o compartilhamento dos territórios com o Brasil e Guiana, especialmente a de número 9 correspondente ao Rupununi com as comunidades indígenas concentradas muito próximas ao limite da fronteira. Na parte de floresta, estão as regiões 1 e 2, enquanto, em direção ao Oceano Atlântico, estão as regiões 3, 4 (Bartida), com grande exploração de garimpo e para onde se deslocam muitos brasileiros), a 5 e 6 .
} 
ampla no que diz respeito às percepções oriundas de diferentes localidades, inclusive internacional, porém convergem para a mesma questão de visibilidade e reconhecimento identitário.

\section{ESTRATÉGIAS DE COLONIZAÇÃO PORTUGUESA E OS INDÍGENAS EM RORAIMA}

Roraima é um dos mais novos estados brasileiros criados a partir da Constituição Federal de 1988. Sua ocupação deu-se pela perspectiva de preservação do território nacional, quando em 1621, a Coroa Portuguesa instituiu o Estado do Maranhão e o Estado do Grão-Pará, sob o governo do Marquês de Pombal, como uma unidade administrativa independente, ligada diretamente a Lisboa (FARAGE, 1991). Foi justamente o extrativismo, apoiado na mão de obra indígena, que caracterizou o Grão-Pará como uma "área colonial periférica".

A viagem do Capitão-mor Pedro Teixeira, em 1639, a serviço da Coroa Portuguesa, mudou o nome do principal rio do Estado, até então conhecido pelos nativos de Quequene ou Quelsuene para rio Branco (BRASIL, 2008). Esse fato marcou o início da construção política dessa região no Brasil. Na ocasião, foi fundada a Capitania de São José do Rio Negro, com a ocupação do médio Amazonas pelos portugueses, tendo como porta de entrada o transporte fluvial, através do Rio Branco (FERRI, 1990). Esse rio foi, durante séculos, a única via de acesso e responsável por permitir as incursões de exploração e a ocupação da região por conquistadores vindos do Pará (VIEIRA, 2007).

Sem muitos relatos históricos, há um silêncio que recobre essa fase inicial da ocupação portuguesa na região, conhecida por atividades clandestinas como extração de drogas do sertão e apresamento dos indígenas por particulares, "à revelia dos objetivos e determinações do Estado" (FARAGE, 1991, p. 56). Essa complexa conjuntura local apresentada fez da colonização do Rio 
Branco uma prioridade central para os portugueses em diversas estratégias de ocupação, mediados pela ação militar de acesso e controle regional.

O papel da igreja católica de "civilização" dos indígenas, mediada pela práxis catequética natural da conversão, demarcou o início de conflitos entre indígenas e não indígenas. Nos aldeamentos, Repetto (2008) esclarece que a ação tutelar pelos diretores religiosos se ancorava em uma autoridade, essencialmente etnocêntrica, ao impor hábitos aos indígenas, diferentes do seu modo tradicional. Tal influência religiosa aliada às políticas luso-brasileiras facilitou o uso da força de trabalho escravo indígena para o desenvolvimento de uma economia agrícola e pesqueira da soberania portuguesa em território indígena.

As demais providências tomadas pela Coroa Portuguesa para posse do território impactaram diretamente a população nativa do vale do rio Branco (BARBOSA, 1993). Vieira (2007) sumaria que o estabelecimento das fazendas nacionais adicionou mais opressão aos indígenas. Nesse contexto o autor informa que, principalmente, os Macuxi e Wapichana passaram a ser "agregados” às margens de tais fazendas, uma vez que para estes não se reconhecia mais a posse da terra. Diante desse cenário de contato interétnico, a cultura indígena encontrava-se completamente relativizada pela cultura da sobreposição.

Tais ações e ideologias políticas deixaram marcas profundas no processo de formação da região e seus habitantes, destacadas no contexto nacional por suas particularidades geopolíticas e socioculturais. Antropologicamente, sob a assimetria da cultura dominante, os povos indígenas enfrentaram políticas de invasão e ocupação dos seus territórios desde a década de 1770. Atravessou, portanto, desde o Grão Pará, onde se localizava a região do vale do Rio Branco, as "políticas administrativas do Brasil Monárquico, Republicano, Militar, Democrático até os dias atuais" (OLIVEIRA; SOUZA, 2010, p. 65). 
No percurso histórico analisado sob uma discussão antropológica acerca dos nexos que envolvem esses paradigmas, Laraia (2008) justifica que tal postura etnocêntrica é decorrente de uma construção cultural dominante, que, ao menos no contexto da modernidade, é feita a partir do século XVII, a serviço das potências do colonialismo. Esses modelos acabaram se codificando, como se todos devessem seguir a mesma normatização imposta por essas sociedades dominantes.

\section{IMPACTOS CULTURAIS SOBRE OS INDÍGENAS MACUXI E WAPICHANA}

Para os indígenas, desde o processo da colonização portuguesa, os encontros com a sociedade não indígena sempre figuraram como trágicos, pois prevalecia pelas frentes pioneiras e frentes de expansão a concepção de que estes estavam no mesmo patamar dos animais. 0 fato de tomá-los fora da fronteira humana resultou em muitas perdas, não só de vidas, mas também de elementos culturais (MARTINS, 1997). Foram questões que deixaram marcas que perpassam, atualmente, por questões identitárias.

Certamente por serem os Wapichana os povos habitantes da região central da ocupação portuguesa em Roraima, Farage (1991), destaca que foi a etnia mais duramente afetada em seus aspectos sociais, culturais e identitários, pela estratégia dos aldeamentos missionários. Já a leitura que se faz no período em questão com relação ao confronto com a cultura Macuxi, Santilli (1994), evidencia que vinte e oito fazendas nacionais se situavam nas regiões do vale do Tacutu, território em que vivia tradicionalmente a grande parcela da população Macuxi. Portanto estase converteu na estratégia de colonização do contato português que mais lhes atingiu.

Com efeito, fator de caráter socioespacial e territorial foi confirmado na etnografia feita por Dielci Bortolon (2014), em três 
comunidades da TI Araçá de predominância populacional Macuxi. A pesquisadora constatou que a referida área foi demarcada em ilhas (pequenas porções de matas) que servem para delimitar o território de cada comunidade, e esta em relação às áreas de fazendas que se encontram em seu entorno.

Historicamente, os Wapichana foram os primeiros habitantes do vale do rio Branco. Porém Vieira (2007) registra que a partir do século XVI, os Macuxi iniciaram suas jornadas migratórias, ao fugir dos espanhóis e guerras intertribais, quando avançaram até territórios do Rupununi, na Guiana. Nesse processo de mobilidade tradicional, invadiram os territórios dos Wapichana com quem passaram a disputar espaço. Nesse aspecto, Melo (2013) atesta que a convivência entre as duas etnias nem sempre foi pacífica e amistosa. Contudo, nos dias de hoje, há comunidades Macuxi e Wapichana num mesmo território, inclusive comunidades mistas (FERRI, 1990).

Com efeito, fundamentado em Cabral (2007), constata-se que os territórios são espaços construídos e desconstruídos por meio das relações sociais, sujeitos a transformações históricas produzidas por diferentes grupos humanos. Já a territorialidade pode ser concebida como uma categoria em que se concentram os espaços com significações individual e social, ou seja, é a projeção da identidade. Embora essas comunidades etnicamente mistas tratem-se de espaços permeados de identidades e territorialidade distintas, tem-se de Burke (2010, p. 14) que "não existe uma fronteira cultural nítida ou firme entre grupos, e sim, pelo contrário, um continuum cultural". Assim, não existe uma divisão rígida, podendo-se conceber uma convivência amistosa entre esses grupos étnicos.

Melo (2013, p. 119) esclarece que Macuxi e Wapichana uniram-se também na área urbana de Boa Vista, "em torno das demandas socioculturais que constroem conjuntamente, já que as experiências obtidas na cidade são similares no que tange à 
interlocução com as instituições públicas". Em outras palavras, os indígenas perceberam que suas demandas comuns provocam, de forma subjetiva, uma consciência de confraternização entre eles, reafirmando o pertencimento étnico, e, em certa medida, rompendo com certos paradigmas da distinção. Assim reestruturam seus saberes através de novas formas de conexões que são emblemáticas para suas articulações e sobrevivência.

\section{PAPEL DOS INDÍGENAS NA FORMAÇÃO ESPACIAL E SOCIOECONÔMICA DE BOA VISTA}

Boa Vista é oriunda de um povoado formado em torno da fazenda Boa Vista ${ }^{4}$ do Carmo, fundada nos anos de 1830, por um oficial do Forte São Joaquim. Na República, essa localidade passou a chamar-se Boa Vista do Rio Branco; quando desmembrada do antigo município amazonense de Moura - por meio do decreto $\mathrm{n}$ 49 de 9 de julho de 1890 -, foi elevada à categoria de município do Amazonas. Era o único povoamento caracteristicamente urbano da região, concentrava, portanto, toda atividade política, administrativa e militar local (BARBOSA, 2003), apesar de ainda apresentar uma simples estrutura. Posteriormente, no Estado Novo - pelo Decreto-Lei 5.813 de 13 de setembro de 1943 - desmembrou-se do Estado do Amazonas, quando foi criado o Território do Rio Branco do qual se tornou a capital (FERRI, 1990).

Localizada na mesorregião Norte de Roraima, à margem direita do rio Branco, Boa Vista é a única capital brasileira situada ao norte da linha do Equador. Somam-se 126 anos de existência,

\footnotetext{
${ }^{4}$ Segundo Freitas (2007), o oficial militar, denominou a fazenda com este nome em referência a sua admiração pela paisagem que a circundava, também aclamada pelos primeiros desbravadores, por sua grande beleza formada pelo rio Branco, igarapés, vegetação ribeirinha e praias. Referendado por Magalhães se aventou a possibilidade de mudar esse nome para Parima ou Uialã, em virtude da homonímia com outras cidades de demais estados brasileiros, porém o povo não permitiu.
} 
contudo, sua estrutura cosmopolita estende-se até aos dias presentes. A cidade conta com 50 bairros e avança, constituindo-se como o lugar receptivo de grande fluxo de migrantes tanto em âmbito nacional quanto internacional ${ }^{5}$. Todavia, para os povos indígenas trata-se apenas de deslocamantos espaciais. Os fluxos e mobilidades indígena em regiões de fronteira é discutida na literatura apenas como deslocamento, considerando que sua mobilidade trata-se de um processo ancestral no território, posteriomente, demarcado físico e politicamante pelos três países que formam o marco da Tríplice Fronteira do Extremo Norte do Brasil.

Essa realidade dos deslocamentos indígenas nas fronteiras cria uma nova questão, quando se abordam processos identitários e ressignificações culturais frente ao trânsito desse intenso contato interétnico. De acordo com Pereira (2005 , p. 11), "a riqueza que se constrói como reflexo das relações interétnicas e entre as nacionalidades tem implicações no universo simbólico das pessoas e no modo como elas expressam a diversidade cultural da fronteira". De fato, percebe-se que as culturas se encontram no confronto, e é aí que o particular vai se destacar, e as culturas não se perdem.

Narrativas feitas por pesquisadores, viajantes, etnólogos, missionários, acerca da composição populacional dos poucos e pequenos povoados do vale do Rio Branco, deixam evidente que Boa Vista estabeleceu-se sob a presença indígena. Contextos da viagem do francês Henri Cordeau pelo Rio Branco em 1887, destacados por Ferri (1990) e Farage (1997), registram um contingente indígena em Boa Vista, compondo dois terços do total dos habitantes. Ainda no começo do século XX, com a ocasião da presença

\footnotetext{
${ }^{5}$ Segundo o Instituto Nacional de Estatística (INE, s.d.), no contexto da mobilidade humana, a migração é definida como todos os movimentos de pessoas de um país a outro, ou de um lugar geográfico a outro dentro de um mesmo país, com mudança de residência. Salienta-se que esse fenômeno divide-se em dois aspectos, no primeiro caso trata-se de migração internacional; já no segundo, tem-se a migração interna.
} 
missionária dos padres beneditinos ${ }^{6}$ no ano de 1909 (BARBOSA, 1993), Boa Vista contava com cerca de 10 mil habitantes, porém somente três mil eram mestiços ou brancos ${ }^{7}$, os $70 \%$ restantes eram indígenas.

Para esse contexto, a tradição oral dos Macuxi e Wapichana, traz elementos que permitem estabelecer uma ligação com o esse passado histórico. Doravante, trás luz à discussão do entendimento para o atual deslocamento espacial dos indígenas para Boa Vista. Recentes produções historiográficas têm revelado aspectos importantes da memória ancestral indígena sobre a região onde se situa Boa Vista. Depoimentos coletados por Oliveira e Souza (2010), acerca da trajetória indígena, atestam que seus antepassados identificavam o espaço outrora ocupado pela atual cidade de Boa Vista como um conjunto de malocas denominado Kuwai Kîrî. No século XIX, era compreendido como o local onde moravam os melhores rezadores e, por esse motivo, atraía os demais indígenas, em deslocamentos constantes em busca de cura para alguma enfermidade física ou espiritual.

Essas informações, ainda carentes de estudos aprofundados, abrem nexos para novas reflexões acerca da participação efetiva da expressão cultural indígena na origem da capital, principalmente pela "ausência dos povos indígenas na construção da historiografia oficial vigente sobre a formação da cidade" (MELO, 2012, p. 26).

\footnotetext{
${ }^{6}$ Situação em que foi edificada a prelazia dos Beneditinos. Segundo Oliveira (2011), o prédio edificado em 1907 foi dirigido pelos Monges Beneditinos até 1944, onde funcionou como hospital de 1924 até 1944. Os Monges Beneditinos encerraram sua Missão em Roraima em 1948, quando foram substituídos pelos Padres da Consolata. Na década de 1950 (em 1950), tornou-se a sede do governo estadual, assumindo um caráter de centro político-administrativo. Atualmente o prédio é sede da Diocese de Roraima (Ordem da Consolata). Faz parte do Projeto Raízes, que recuperou o Centro Histórico e Cultural da cidade, através de políticas de incentivo e desenvolvimento da cultura, financiado pelo governo federal.

${ }^{7}$ A palavra "branco" é o termo muito utilizado pelos autores à época para diferenciar dos indígenas, hoje é também utilizado a palavra "não indígena", que tem o mesmo significado, o que foi preferido neste trabalho.
} 
São dados que apontam para a dialética entre memória e identidade, na perspectiva sedimentada por Candau (2012), quando o autor afirma que a memória vem fortalecer a identidade.

Alicerçados pela predisposição de uma demanda identitária, os indígenas reativam suas memórias ao incorporar certos aspectos do passado para construir novos argumentos para se rediscutir a gênese da capital, bem como um "novo olhar a partir dos indígenas que se de deslocaram das malocas para visitar os parentes no Kuwai Kîrî, que é hoje Boa Vista" (OLIVEIRA; SOUZA, 2010, p. 63). Na legitimidade da presença indígena local e acepção de posse de seus territórios ancestrais, os sujeitos participantes da pesquisa comumente referem-se aos indígenas que se encontram na área urbana de Boa Vista como "moradores da Maloca Grande".

Para o contexto histórico de predominância populacional indígena no povoado que deu origem a Boa Vista, Ferri (1990) argumenta que, embora constituíssem a maioria, esses povos não tinham direitos nem poder de decisão política. Uma vez que a massiva presença indígena vivia numa condição de submissão socioeconômica prestando serviços ao sistema de produção regional, num regime de exploração, poderia caracterizar-se como escravocrata.

Impactada pelo papel indígena na atividade extrativista que predominava na região, Farage (1991, p. 26) atesta que era "[...] pelo número de índios que se media a riqueza de um morador". Essa "riqueza" tornava-se mais densa, na medida em que o recrutamento de mocinhas indígenas ia instituindo-se na sociedade roraimense. 0 papel de "criadas" era desenvolvido desde as casas nas fazendas até as residências em Boa Vista (FERRI, 1990; FRANK, 2014). Conforme Santos (2014, p. 141), ainda hoje, é "normal senhoras brancas buscarem jovens índias guianenses com promessas de estudos para trabalhar na cidade", porém o principal objetivo é o serviço doméstico.

Atualmente, desvelou-se, nos relatos de vivências de duas colaboradoras da pesquisa, o papel exercido por elas, quando 
fizeram parte desse sistema já enraizado socialmente. São personagens que fizeram parte de uma geração que vivenciou o trabalho escravo doméstico, e, testemunham que tal atividade, sucintamente, ainda se estende até os dias atuais. Com efeito, as mulheres indígenas figuram entre os vinte e cinco por cento dos chefes de família (IBGE, 2012), cuja principal atividade desenvolvida é o serviço doméstico.

A mesma situação social de exploração se deu para o sexo masculino, com reflexos atuais no desenvolvimento de atividades informais, cuja forma de pagamento chega a ser "negociada" em algum valor em dinheiro, que lhes permite uma renda mensal agravada pela falta de qualificação profissional - variando de meio a um salário mínimo (SOUZA, 2009). Santos (2014) observa que os trabalhos que os jovens encontram na cidade, nas serrarias, na construção civil são pouco remunerados, e os empregadores quase não respeitam as leis trabalhistas. Mesmo diante dessas adversidades, Boa Vista representa o lugar de oportunidades para diversas famílias indígenas, incluindo aqueles que vieram de territórios fronteiriços. Segundo os coordenadores das agências pesquisadas, o maior contingente trata-se de indígenas Wapichana, oriundos da área de fronteira guianense.

Embora sendo reconhecido apenas como força de trabalho (FERRI, 1990), com participação política e social considerada pouco significativa, convém observar que esta realidade indígena, descrita na lógica da história, valida atualmente a participação destes no desenvolvimento socioeconômico da capital. Essa perspectiva pode ser tomada como análise sob a dinâmica do espaço, e da interação social nele estabelecido. Do ponto de vista da dimensão espacial, por ser concebido como uma categoria geográfica de interação social, consequentemente cada grupo humano inserido nesse arranjo imprime suas singularidades.

A acepção tomada anteriormente como pertinente na discussão do contexto indígena em Boa Vista ampara-se em Cabral 
(2009), quando o autor trata a validação das diversas práticas sociais como recurso analítico à compreensão das mudanças, paradigmas e configurações espaciais do mundo contemporâneo, uma vez que todas as identidades inseridas no contexto espacial deixam sua parcela de contribuição, procurando atender à sociedade naquilo que lhes seja proposto. Essa discussão também tem sua correlação em Marshal Sahlins (1997), quando atesta que os indígenas indigenizam a modernidade, no sentido de imprimir seus costumes na sociedade ocidental - particularmente, no caso do locus da pesquisa - mesmo quando estão nas cidades.

\section{PROCESSO MIGRATÓRIO E A INVISIBILIDADE INDÍGENA EM RORAIMA}

O quadro populacional de Boa Vista composto pela maioria indígena começou a retrair a partir da época do apogeu da borracha (1910-1913), com a chegada de um grande contingente migratório, sobretudo de nordestinos, para a Amazônia. Isto se deu, conforme Ferri (1990) e Farage (1997), quando na queda dessa atividade, o rio Branco, vislumbrou-se como atrativo dessas populações, devido às suas reservas minerais e possibilidade de expansão da atividade agropecuária. Conforme Diniz e Santos (2006), no período de 1920 a 1950, houve um aumento populacional de Boa Vista em 80\% aproximadamente. Porém a grande explosão demográfica de Roraima ocorreu no período de 1980 a 1991.

Dados do IBGE revelaram o fenômeno de uma migração vertiginosa, quando a população do estado quase triplicou (DINIZ; SANTOS, 2006 ). Sobre o impacto da ascendência dessa curva no gráfico migratório, pode-se levantar dois principais fatores. Segundo Santos (2013 ), um deles trata-se da política de legalização territorial, por meio de uma colonização direcionada, a partir de 1985, com a criação dos Assentamentos do Instituto Nacional 
de Colonização e Reforma Agrária (INCRA) e do Instituto de Terras e Colonização de Roraima (ITERAIMA). Essa política beneficiou diversas áreas do Nordeste, com prioridades para os nativos do estado do Maranhão, que, desde a década de 1940, já representavam o principal grupo de imigrantes (DINIZ; SANTOS, 2006).

0 outro importante fator para a migração se deu por meio da identificação da presença de minérios de valor econômico, como consequência da divulgação dos dados do RADAM-Brasil (VALE, 2013). Com efeito, a descoberta de ouro e diamantes na porção setentrional de Roraima, em meados dos anos 1980, trouxe milhares de garimpeiros ao Estado, incentivados pela imprensa e setores interessados na exploração mineral. Estima-se que mais de 40.000 indivíduos estiveram envolvidos diretamente nessa empreitada, entre 1987 e 1991, sem contar aqueles que se envolveram indiretamente com o garimpo, trabalhando em atividades de apoio ou desenvolvendo o comércio na cidade de Boa Vista (DINIZ; SANTOS, 2006).

Paralelamente às atividades garimpeiras, reivindicações constantes das lideranças indígenas em suas assembleias pediam providências federais com relação aos nefastos danos ambientais. Frank (2014, p. 44), atesta que a "mobilização e pressão do movimento indígena ganharam consistência no âmbito local, com projeção nacional e internacional, apoio de pesquisadores (as) e organizações sociais, o que levou ao fechamento de garimpos pelo presidente da República Fernando Collor de Melo no início dos anos de 1990". Fato que obrigou um massivo deslocamento de garimpeiros para a área urbana de Boa Vista, engrossando as fileiras de pobreza na periferia. A autora atesta que esse inchaço na cidade, conduziu à criação de novos bairros, sobretudo, na zona oeste, mudando a configuração e a paisagem do espaço boa-vistense. Esse fluxo trouxe um perfil multicultural à cidade, conceituada no âmbito do contexto artístico local como um "caldeirão cultural" (OLIVEIRA, 2011). 
Ferri (1990, p. 24) registra que os indígenas que se encontravam na cidade sofreram diretamente o processo de inchamento urbano, e avalia: "se, de um lado, a situação de extrema pobreza na qual se encontravam esses últimos migrantes os aproximava dos indígenas - parte mais pobre da população de Boa Vista -, de outro lado, tornaram-se seus rivais na disputa dos poucos trabalhos manuais existentes". Embora nos bairros periféricos de Boa Vista indígenas e nordestinos aprenderam a conviver com a mesma situação de exploração, a autora faz a seguinte comparação: "Mas qualquer homem branco, mesmo o mais pobre e analfabeto, tinha sempre uma vantagem comparados aos indígenas: era branco, "civilizado". De fato, muitos migrantes, que chegaram a Boa Vista, em busca de oportunidades socioeconômicas, conseguiram com o tempo vislumbrar melhores lugares na sociedade local em comparação àqueles ocupados por esses migrantes em seus lugares de origem. Fato que substancia os discursos políticos partidários como "Estado de oportunidades", no sentido de potencializar o sucesso socioeconômico promovido endogenamente.

Como consequência mais visível desse desnível de oportunidade para os indígenas, Melo (2012) observa na contemporaneidade uma dinâmica política, econômica e social, desfavorável aos Macuxi e Wapichana em Boa Vista. Depreende-se, das observações da autora, que a invisibilidade que repousa sobre a presença dos indígenas no contexto miscigenado culturalmente de Boa Vista se traduz em ausência de uma estrutura político-administrativa nas esferas públicas, que adicionam limitações socioculturais à sua sobrevivência.

\section{RESSIGNIFICAÇÕES PARA BUSCA DA VISIBILIDADE IDENTITÁRIA INDÍGENA}

Uma parcela significativa de pesquisas, censos e diagnósticos realizados com indígenas em área urbana de Boa Vista (SOUZA; 
REPETTO, 2007; OLIVEIRA, 2010; MELO, 2012), atestadas, em pesquisa de campo, revelam que os grupos socialmente hegemônicos não são capazes de subtrair a presença e vivência dos indígenas pela repressão social e/ou política. Doravante, transforma-se em possibilidades de transcender essa realidade indígena em manifestações políticas.

Desse modo, os Macuxi e Wapichana ampliam sua condição de pessoa humana com reivindicações políticas de melhorias de condições de vida. Aspecto que revela uma autoafirmação étnica com maior apreço e respeito à sua cultura, fomentando, por meio de agências indígenas, a "construção uma narrativa de pertencimento que inter-relaciona os aspectos socioculturais engolidos pela história oficial e, posteriormente, pela sociedade em posse do poder público" (MELO, 2012, p. 50).

Em contraste, é comum, para a sociedade não indígena no Brasil, até mesmo na formação superior, associar os povos indígenas como pessoas vivendo em aldeias distantes e fechadas, localizadas nas regiões de florestas (SANTOS, 2014). Decerto esse fenômeno de reconhecimento dos indígenas como novos habitantes das cidades modernas impacta a sociedade não indígena como algo novo. $\mathrm{Na}$ análise teórica da prática e política de identidade indígena e sua forma de realização no espaço da cidade, Virtanen (2010) discute que a presença indígena em áreas urbanas da Amazônia tornou-se mais visível quando essas populações negociaram seus próprios espaços, atuando em novos contextos reservados apenas para a sociedade dominante.

Ao partilhar de pensamento semelhante, Castro (2007) destaca que as palavras índios e natureza "despertam" simpatia na atual consciência ecológica de preservação ambiental das culturas não indígenas. Novamente evoca a ideia projetada sobre a figura indígena de seres imersos e em sintonia tenaz com a natureza. Por outro lado, observa-se que essa postura está diretamente relacionada aos estigmas já concretamente definidos pela sociedade 
dominante, para referir-se aos grupos indígenas em contexto urbano, como "destribalizados", "desaldeados", "imigrantes", "caboclos", "índios urbanos", "índios citadinos” ou "indígenas da cidade" - inclusive concebidos pela produção intelectual (MELO, 2012 ).

Conforme pesquisa em campo, pode-se perceber que esses termos são frequentemente utilizados nos discursos indígenas convertidos como instrumentos de visibilidade para validar, na lógica da etnicidade, sua presença no contexto socioespacial da cidade. De fato, nas urdiduras e contrastes das relações sociais citadinas, os indígenas encontram elementos tomados como importantes para continuarem a afirmar-se indígenas. Em outras palavras, valem-se até de expressões pejorativas, cotidianamente usadas para referir-se a eles, e as ressignificam no emprego de forças para reafirmação de suas identidades étnicas em Boa Vista: "São muitas as maneiras das pessoas na cidade se referirem a nós que estamos aqui..., a gente sente que é sempre preconceituosa... Bom, pelo menos estamos sendo vistos, né?" (DIÁRIO DE CAMPO, 09/04/2016, p. 1).

Para um coordenador de agência indígena, cada enfrentamento de conflitos, principalmente oriundos de posturas preconceituosas, os provoca a assumirem sua identidade étnica: "Percebe-se muito preconceito, os não indígenas dizem que somos caboclos, às vezes estou em supermercado e ouço o cochicho deles em relação a outros indígenas que lá se encontram. Às vezes, pedem-me confirmação, achando que não sou indígena, e eu digo: são indígena sim, e eu também!" (ES4, 2015, p. 2).

Por outro lado, esses diálogos em campo revelam alguns aspectos perceptíveis pelos sujeitos, em relação aos nexos constantes da transitoriedade que operam sobre sua identidade étnica (SANTOS, 2014). Com efeito, aqui cabe fazer uma reflexão teórica referente ao problema manifesto da identidade no contexto dos fragmentos de relatos anteriores. A ideia de identidade como uma 
"celebração móvel", formada continuamente pelos sistemas culturais, de Stuart Hall (2011), confirma as ressignificações dadas pelos sujeitos da pesquisa a partir das discriminações socioculturais por eles sofridas. Ao adotar tais "termos" como elementos de visibilidade indígena, automaticamente a identidade étnica, já ocupada por uma variedade de hábitos indígenas e não indígenas dentro das redes sociais complexas, utiliza processos tomados como significativos da consciência, como parte estratégica para romper a alteridade da indianidade ${ }^{8}$ (VIRTANEN, 2010).

\section{APROPRIAÇÕES PARA O “SER” ÍNDIGENA}

Muitas ressignificações feitas pelos indígenas no contexto urbano expressam particularidades de interesses subjetivos e institucionais, às vezes mais de conflitos que de consenso. Nisto se concorda com Santos (2014), ao observar que as vivências dos povos indígenas na cidade denotam situações de conflitos, uma vez que eles enfrentam preconceitos nas mais diferentes situações. Ao ser indagado acerca dos principais hábitos fora do ambiente doméstico, como no trabalho ou nos ambientes públicos, um sujeito da pesquisa comenta:

Sempre há um cuidado em procurar não demonstrar muito a identidade indígena na cidade, por conta do preconceito que é muito grande. Certo dia estava na fila do banco, conversando na língua materna com uma indígena e uma pessoa me perguntou

\footnotetext{
${ }^{8}$ Termo que representa símbolos de conotação biológica indígena, ou seja, os critérios de indianidade, representam a cor da pele, cabelos escuros e lisos, prega mongólica e por outros, tomada pela sociedade não indígena, como uma qualidade essencial que tem de ser incorporado em formas visíveis. Paradoxalmente, Virtanen (2010) esclarece que embora os povos indígenas tivessem que minimizar essas diferenças, agora se espera deles uma exibição, para então serem considerados como cidadãos indígenas de pleno direito. Porém as novas definições de indianidade encontradas entre os jovens urbanos nativos amazônides mostram que os jovens se envolvem em muitos estilos de vida diferentes. Assim, eles têm vários corpos "nativos" e "não nativos", permitindo-lhes beneficiar de contextos sociais distintos.
} 
se estávamos falando japonês, então lhe expliquei que estávamos falando uma língua indígena regional que era Wapichana. (ES4, 2015, p. 2).

0 fragmento anterior mostra que o processo de identidade étnica, por vezes torna-se mais ajustado e reafirmado pela subjetividade indígena, do que anulado diante da negação do outro. Aspectos internos e singulares nas significações descritas nos depoimentos revelam que os indígenas resistem a serem designados por qualquer outro termo que não seja de fato o "ser indígena". Porém, no rol de termos a eles referidos, a maior resistência está em ser denominado de "caboclo":

Saiu da comunidade, está "desaldeado", ou seja, mas eu não deixei de ser índio!.. [...] Fazer que nem o outro: É um orgulho dizer eu sou! Porque, outra coisa, a maioria do indígena, ele fica indignado, se sente mais discriminado, se você chamar de caboclo. Isso eu já vi tanto na cidade, como na comunidade. A gente prefere ser chamado de índio. [...] eu já conversei com muita gente, ele se sente mais discriminado quando é chamado de caboclo. Agora não, se tu chamar de índio, aí... [...] quando a gente chega pra nossa realidade: É índio! Aqui tem índio, não tem caboclo (risos). Aí existe isso, então, eles sentem isso, e eu vejo na comunidade. Nas comunidades, e eles não gostam que chame de caboclo, e aí eu fiquei pensando, mas "por quê", existe uma lógica? Aí eles dizem: "eu não gosto, eu fico zangado quando um branco me chama de caboclo!. [...] E é a mesma coisa aqui na cidade, os da cidade eles não gostam, e isso eu já presenciei muito, e no aterro sanitário também, quando eles dizem que caboclo só sabe... que o caboclo é preguiçoso, o caboclo tá catando lixo, mas eles dizem eu prefiro que eles chamem "o índio que cata lixo" "o índio que é preguiçoso" (risos) mas não o caboclo! (ES1, 2015, p. 4).

No contexto regional, denomina-se "caboclos" aos indivíduos que, relacionalmente, apresentam miscigenação com antepassados indígenas. Segundo Cardoso de Oliveira (2000), esse termo define o que se mostrou ser uma categoria social estratégica para a interpretação de identidades limite: entre ser e não ser índio; desse modo, pode-se afirmar que constituem grupos que se arti- 
culam dentro e através de fronteiras étnicas (BARTH, 2000). Ou seja, o termo caboclo soa como algo genérico.

Ao discutir a mesma denominação com os colaboradores indígenas de sua pesquisa, Santos (2014) aborda que, na Amazônia, a definição de caboclo foi inicialmente usada como sinônimo de tapuio, termo genérico de desprezo que os povos indígenas usavam quando se referiam a indivíduos de outros grupos. $\mathrm{Na}$ pesquisa da autora realizada com indígenas nos canteiros de obras de construção civil em Boa Vista, cinco dos noves sujeitos da pesquisa demonstraram não se incomodarem quando se referem a eles como "caboclo", dizem que já estão acostumados. Porém a autora afirma que as percepções retratadas nessa escuta revelam que aceitam a condição de ser "caboclo", no caso já descrito de apropriarem-se do termo nos discursos, apenas por considerarem necessário, embora não se autoidentifiquem.

A pesquisa bibliográfica acerca da presença indígena em áreas urbanas revela-se marcante ao observar que estes se concentram nas periferias das cidades brasileiras. Contudo registros em diário de campo do discurso indígena em espaço acadêmico da UFRR atestam que, principalmente os indígenas em nível de stricto sensu, resistem serem considerados moradores de periferia em Boa Vista: "nós não somos moradores de periferia... Periferia fica nos arredores da cidade, e nós fazemos parte da cidade!" (DIÁRIO DE CAMPO, 09/04/2016, p. 1).

A leitura que se faz do fragmento é que a apropriação intelectual tem ajudado os indígenas, a ressignificarem tendências da cultura nostálgica, que lhe foi reservada pela teoria do desalento ${ }^{9}$.

\footnotetext{
${ }^{9}$ Em resposta às críticas contemporâneas à ciência antropológica, Marshall Sahlins (1997), na primeira parte do artigo "O "pessimismo sentimental" e a experiência etnográfica: por que a cultura não é um "objeto" em via de extinção", resgata a nostalgia antropológica acerca da vida tribal, que, em contexto urbano, estaria desmoronando-se em visões globais da hegemonia ocidental. E destaca: "A teoria do desalento [despondency theory] foi o precursor ideológico da teoria da dependência. Nos anos 50 e 60, pairava uma certeza lúgubre de que os séculos de imperialismo ocidental, o longo
} 
Segundo esta teoria, certos grupos nativos eram tomados como "coitadinhos", morando em guetos de periferia. Para os indígenas que se encontram nas cidades, estes seriam os "desaldeados", ou seja, àqueles que fisicamente e culturalmente estariam fadados à morte, onde sua cultura estaria "se desintegrando sob o assédio da ordem capitalista mundial" (SAHLINS, 1997, p. 42). Para este contexto teórico, segundo o autor, o conceito de cultura era interpretado como um instrumento de diferenciação social, ao servir como parâmetro para marcar diferença de costume entre povos e grupos; portanto levaria a legitimar as múltiplas desigualdades, que para esses seria um meio ideológico de vitimação.

Porem, atualmente, vê-se que tais grupos sociais estão mais fortalecidos; aqueles que pareciam desaparecer, ou se integrar à sociedade nacional, mostram seus avanços. Na história constitucional brasileira, a atual Carta Magna avançou quando reconheceu pela primeira vez, em seus art. 231 e 232, a organização social, costumes, línguas, crenças e tradições dos povos indígenas. Dessa forma, encontram-se nas cidades ressignificando seus costumes numa relação/construção que se estabelece nesse espaço geográfico, ou seja, pelo movimento das coisas que estão sendo por eles construídas. Cabral (2007) complementa que o espaço pode ser visto como decorrente da relação da ação sobre um objeto e vice-versa, constituindo um arranjo do qual dependem as práticas sociais. Esses caminhos têm um papel de fundamental relevância na hermenêutica espacial sob o ponto de vista dos próprios sujeitos.

desenvolvimento do subdesenvolvimento, haviam devastado as instituições, valores e consciência cultural dos povos (ex-)aborígines em todo o mundo". Tomados por essa teoria, algumas pesquisas procuravam retratar teorias da modernização que tinham os mesmos pressupostos. 


\section{CONSIDERAÇÕES FINAIS}

0 artigo discute pelo menos quatro dimensões que envolvem a busca de visibilidade da identidade indígena para a cidade de Boa Vista. Inicialmente verifica-se que os indígenas habitantes tradicionais da Tríplice Fronteira do Norte do Brasil, sofreram um processo de invasão de seu território, ocasionando conflitos que perpassam seu cotidiano étnico.

Valendo-se da historiografia, pelo método da memória oral e produção acadêmica acerca de registros arqueológicos para a região hoje ocupada pela cidade de Boa Vista, a subjetividade indígena percebeu que tais aspectos podem ser tomados como instrumentos para legitimar sua presença na demografia populacional da cidade. Ao reconhecer que a região hoje ocupada pela "Maloca Grande", outrora era uma "grande maloca" ocupada por uma "elite" indígena no trato com questões espirituais, os indígenas reconfiguram sua identidade étnica por meio de discursos que resgatam antecedentes históricos, portanto reforçam o sentimento de pertencimento ao referido espaço.

0 regime de trabalho escravocrata desenvolvido por este no processo de colonização da região, consistiu em outra dimensão tomada para legitimar a identidade indígena como elemento de visibilidade para participação e apropriação da configuração espacial da cidade. Esses fatos atestam sua presença e parcela de contribuição, portanto demarcam a busca de visibilidade da identidade étnica por meio da participação socioeconômica do trabalho.

Outra dimensão tomada para a afirmação da identidade étnica está nos paradigmas que os impulsionam diariamente a apropriarem-se de reatualizações culturais. Eles perceberam que sua luta não consiste na hostilidade do "arco e flecha", mas em elementos ressignificados da própria sistematização política dos não indígenas. Neste sentido, eles se organizaram em agências 
indígenas, no sentido de concorrerem politicamente na busca de suas demandas. Esse aspecto da subjetividade indígena pode ser interpretado como busca de visibilidade por meio de entidade com identidade étnica coletiva.

Finalmente, os indígenas perceberam que suas identidades étnicas são reforçadas quando se apropriam de uma infinidade de situações decorrentes das tensões no ambiente urbano, principalmente aquelas oriundas de posturas preconceituosas. Nesse rol, destacaram-se os termos pejorativos, geralmente usados para referirem-se a eles. Ou seja, os indígenas perceberam que o objetivo de afirmação de sua identidade, de certa forma, se encontraria ali estampado. Portanto, foram caracterizados como busca de visibilidade por meio de termos estigmatizados.

\section{REFERÊNCIAS}

BARBOSA, R. Imbrózio. Ocupação humana em Roraima I: do histórico colonial ao início do assentamento dirigido. Boletim do Museu Paraense Emílio Goeldi, Belém, PA, p. 123-144, 1993. (Série Antropológica).

BARTH, Fredrick. O guru, o iniciador e outras variações antropológicas. Rio de Janeiro: Contra Capa, [1969] 2000.

BRASIL. Amazonas. Roraima e a questão indígena. Boa Vista, RR: Editora Boa Vista, 2008.

BURKE, Peter. Hibridismo cultural. 3. ed. São Leopoldo, RS: Editora Unisinos, 2010.

BORTOLON, Dielci Maria Oliveira. Terra Indígena Araçá/Roraima: continuidades e transformações envolvendo coletividades Macuxi. 2014. f. 170. Dissertação (Mestrado em Ambiente e Desenvolvimento) - Centro Universitário UNIVATES, Lajeado, RS, 2014.

CABRAL, Luís Otávio. Revisitando as noções de espaço, lugar paisagem e território sob uma perspectiva geográfica. Revista de Ciências Humanas, Florinópolis, v. 41, n. 1 e 2, p. 141-155, abr./out. 2007. Disponível em: <https://periodicos.ufsc.br/index.php/revistacfh/article/ view/15626>. Acesso em: 2 jan. 2013. 
CANDAU, Joel. Memória e identidade. São Paulo: Contexto, 2012.

CARDOSO DE OLIVEIRA. Roberto. Os (des)caminhos da identidade. Revista Brasileira de Ciências Sociais, v. 15, n. 42, p. 7-21, fev. 2000. Disponível em: <http://www.scielo.br/pdf/rbcsoc/v15n42/1733.pdf>. Acesso em: 23 jan.2016.

CASTRO, Eduardo Viveiros de. A natureza em pessoa: sobre outras práticas de conhecimento. Revista Mana, Rio de Janeiro, v. 12, n. 2, p. 115-144, 2007.

DIÁRIO DE CAMPO, 9 abr. 2016. Participação no pré-vestibular indígena no campus da UFRR. Boa Vista, RR, 2016.

DINIZ, Alexandre M. A.; SANTOS, Reinaldo Onofre dos. Fluxos migratórios e formação da rede urbana de Roraima. In: ENCONTRO NACIONAL DE ESTUDOS POPULACIONAIS, 15., 2006, 18-22 set. 2006, Caxambu, MG. Anais... Caxambu: ABEP, 2006. Disponível em: <http://www.abep. org.br/ abeporgb/publicacoes/index.php/anais/issue/view/35/ showToc>. Acesso em: 12 maio 2015.

ENTREVISTADO S1 (ES1). Depoimento [2015, p. 1-6]. Entrevistador: Ana Hilda Carvalho de Souza. Boa Vista, RR: s.e., 2015. Gravação em máquina digital. Entrevista concedida a Ana Hilda Carvalho de Souza.

ENTREVISTADO S2 (ES2). Depoimento [2015, p. 1-8]. Entrevistador: Ana Hilda Carvalho de Souza. Boa Vista, RR: s.e., 2015. Gravação em máquina digital. Entrevista concedida a Ana Hilda Carvalho de Souza.

ENTREVISTADO S4 (ES4). Depoimento [2015, p. 1-8]. Entrevistador: 0 autor. Boa Vista, RR: s.e., 2015. Gravação em máquina digital. Entrevista concedida ao autor.

FARAGE, Nádia. As muralhas do sertão: os povos indígenas no Rio Branco e a colonização. Rio de Janeiro: Paz e Terra; ANPOCS, 1991.

FERRI, Patrícia. Achados ou perdidos? A imigração indígena em Boa Vista. Goiânia: MLAM, 1990.

FRANK, Nelita. A experiência de mulheres indígenas Wapichana e Macuxi em deslocamentos na fronteira Brasil-Guyana: um estudo sobre gênero e narrativas autobiográficas. 2014. Dissertação (Mestrado em Sociedade e Fronteira) - Universidade Federal de Roraima (UFRR), Boa Vista, RR, 2014. 
FREITAS, Paulo Rogério de. Reencontrando a primitiva cidade Boa Vista. Revista ACTA Geográfica, Boa Vista, ano I, n. 2, p. 57-68, jul./dez. 2007. Disponível em: <revista.ufrr.br/actageo/article/download/190/354. pdf>. Acesso em: 23 jun. 2015.

GEERTZ, Clifford. A interpretação das culturas. Rio de Janeiro: Guanabara, 1989.

HALL, Stuart. A identidade cultural na pós-modernidade. 11. ed. Rio de Janeiro: DP\&A, 2011.

INSTITUTO BRASILEIRO DE GEOGRAFIA E ESTATÍSTICA (IBGE). Censo Demográfico 2010: características gerais dos indígenas. Rio de Janeiro, RJ, 2012. Disponível em: <ftp://ftp.ibge.gov.br/Censos/ Censo_Demografico_2010/Caracteristicas_Gerais_dos_Indigenas/pdf/ Publicacao_completa.pdf>. Acesso em: 20 jan. 2014.

INSTITUTO NACIONAL DE ESTATÍSTICA (INE). Migração, [s.d.]. Disponível em: <http://smi.ine.pt/Conceito/Detalhes/1826>. Acesso em: 12 jan. 2008.

LAPPE, Emelí. Espacialidades sociais e territoriais Kaingang: terras indígenas Foxá e Por Fi Gâ em contextos urbanos dos Rios TaquariAntas e Sinos. 2015. f. 207. Dissertação (Mestrado em Ambiente e Desenvolvimento) - Centro Universitário UNIVATES, Lajeado, RS, 2015.

LARAIA, Roque de Barros. Cultura: um conceito antropológico. 23. ed. Rio de Janeiro: Jorge Zahar, 2009.

MARTINS, José de Souza. Fronteira - a degradação do outro nos confins do humano. São Paulo: Hucitec, 1997.

MELO, Luciana Marinho de. Fluxos culturais e os povos da cidade: entre os Macuxi e Wapichana de Boa Vista - Roraima. 2012. 156f. Dissertação (Mestrado Profissional de Preservação do Patrimônio Cultural) - Instituto do Patrimônio Histórico e Artístico Nacional, Rio de Janeiro, 2012. Disponível em: <http://portal.iphan.gov.br/uploads/ ckfinder/arquivos/Disserta+\%C2\%BA+\%C3\%BAo\%20Luciana\%20 Marinho\%20de\%20Melo.pdf>. Acesso em: 23 ago. 2015.

A formação sociocultural de Boa Vista - Roraima e os povos Macuxi e Wapichana da cidade: processos históricos e sentidos de pertencimento. Textos \& Debates, Boa Vista, RR, n. 23, p. 115-133, 
jan./jun. 2013. Disponível em: <http://revista.ufrr.br/index.php/ textosedebates/article/view/2167>. Acesso em: 12 out. 2015.

MUSSI, Vanderléia Paes Leite. As estratégias de inserção dos índios Terena: da aldeia ao espaço urbano (1990-2005). 2006. f. 331. Tese (Doutorado em História) - Faculdade de Ciências e Letras de Assis, Universidade Paulista, Assis, SP, 2006.

OLIVEIRA, Reginaldo Gomes de. Projeto Kuwi Kîri: os parceiros. In: OLIVEIRA, Reginaldo Gomes de (Org.). Projeto Kuwi Kîri: a experiência amazônica dos índios urbanos de Boa Vista- Roraima. Boa Vista, RR: Editora UFRR, 2010. p. 01-20.

OLIVEIRA, Reginaldo Gomes de; SOUZA, Eliandro Pedro. Organização dos Indígenas na Cidade - ODIC. In: OLIVEIRA, Reginaldo Gomes de (Org.). Projeto Kuwi Kîri: a experiência amazônica dos índios urbanos de Boa Vista - Roraima. Boa Vista, RR: Editora UFRR, 2010. p. 61-71.

OLIVEIRA, Elialdo R. Reflexão educativa na reconstrução da dignidade da pessoa humana. In: SILVA, Josias Ferreira; SENHORAS, Eloi (Org). Reflexões educacionais a partir de novos talentos. Boa Vista: UFRR, 2012. p.119-142.

- Cidade criativa: perspectiva de desenvolvimento socioeconômico para Boa Vista (RR). RDE - Revista de Desenvolvimento Econômico, Salvador, BA, Ano 13, n. 23, jun. 2011. Disponível em: <http://www.revistas.unifacs. br/index.php/rde/article/download>. Acesso em: ago. 2015.

PAIS, José Machado. Vida cotidiana: enigmas e revelações. São Paulo: Cortez, 2003.

PEREIRA, Mariana Cunha. A ponte imaginária: o trânsito de etnias na fronteira Brasil e Guiana. 2005. 181f. Tese (Doutorado em Antropologia Social) - Centro de Pesquisa e Pós-Graduação sobre as américas (CEPPAC), Universidade de Brasília (UnB), Brasília, 2005. Disponível em: <http://www.ceppac.unb.br/pos-graduacao/teses-e-dissertacoes>. Acesso em: 25 jan. 2014.

REPETTO, Maxim. Movimentos indígenas e conflitos territoriais no Estado de Roraima. Boa Vista, RR: UFRR, 2008.

SAHLINS, Marshall. O "pessimismo sentimental" e a experiência etnográfica: Por que a cultura não é um "objeto" em via de extinção 
A busca pelo reconhecimento da identidade étnica Macuxi e Wapichana no contexto urbano de Boa Vista, Roraima, Brasil

(Parte I). Revista Mana, Rio de Janeiro, v. 3, n. 1, p. 41-73, abr. 1997.

SANTILLI, Paulo. As fronteiras da república: história e política entre os Macuxi do vale do Rio Branco. São Paulo: Lis, 1994.

SANTOS, Alessandra Rufino. Migração de peruanos em Boa Vista/ RR. 2013. 116 f. Dissertação (Mestrado em Sociedade e Cultura na Amazônia) - Universidade Federal do Amazonas, Manaus, 2013. Disponível em: <http://200.129.163.13/portais/anexos/upload/wpcontent/uploads/2013/12/Capa.pdf>. Acesso em: 12 maio 2015.

SANTOS, Roseli Bernardo Silva. Processos de identidade dos indígenas trabalhadores da construção civil na cidade de Boa Vista/RR. Tese (Doutorado em Ciências Sociais) - Programa de Pós-Graduação em Ciências Sociais, Universidade do Vale do Rio dos Sinos (UNISINOS), São Leopoldo, RS, 2014.

SILVEIRA, Edson Damas da; SOUZA, Ádria S. Duarte. Políticas públicas e direitos indígenas. Manaus: UEA Edições, 2011.

SOUZA, Eliandro Pedro de; REPETTO, Maxim; ODIC. (Org.). Diagnóstico da situação dos indígenas na cidade de Boa Vista. Boa Vista, RR: Ióris, 2007.

SOUZA, Ana Hilda Carvalho de. População indígena de Boa Vista/RR: uma análise sócio-econômica. 2009. Dissertação (Mestrado em Economia) Faculdade de Ciências Econômicas, Universidade Federal do Rio Grande do Sul, Porto Alegre, 2009.

TRIVIÑOS, Augusto Nibaldo Silva. Bases teórico-metodológicas da pesquisa qualitativa em ciências sociais: idéias gerais para a elaboração de um projeto de pesquisa. Cadernos de pesquisa Ritter dos Reis. 2. ed. nov. 2001. Porto Alegre: UniRiterr, 2001. v. IV.

UN-HABITAT. Urban indigenous peoples and migration; a review of policies, programmes and practices. 2010. Disponível em: <http://www. unhabitat.org/pmss/listItemDetails.aspx?publicationID=2916>. Acesso em: 23 ago. 2014.

VALE, Ana Lia Faria. Multiterritorialidade e migração em área de fronteira. In: RODRIGUES, Francilene dos Santos Rodrigues; PEREIRA, Mariana Cunha (Org.). Estudos transdisciplinares na Amazônia Setentrional: fronteiras, migração e políticas públicas. Boa Vista, RR: 
Editora da UFRR, 2013. p. 121-153.

VIEIRA, Jaci Guilherme. 0 índio na produção historiográfica de Roraima. Revista do NUSHA/Universidade Federal de Roraima, Núcleo Histórico Socioambiental, v. 1, n. 1, p. 85-102, ago./dez. 2007.

VIRTANEN, Pirjo Kristina. Amazonian Native Youths and Notions of Indigeneity in Urban Areas. Identities, v. 17, n. 2, p. 154175, 2010. Disponível em: <http://www.tandfonline.com/doi/ abs/10.1080/10702891003734961\#.U8v710NdX1Y>. Acesso em: 17 jul. 2014. 